\title{
COMPARATIVE STUDY OF THE MICROSHEAR BOND STRENGTH AND THE SOLUBILITY OF RESIN SEALER WITH AND WITHOUT THE ADDITION OF NANO SILVER
}

\author{
Yousra M. Nashaat *; Hadeel A. Sabry *** and Elham I. Elshaboury ${ }^{* * *}$
}

\begin{abstract}
Aim: To compare the micro shear bond strength and the solubility of resin sealer with and without the addition of Nano silver.

Materials and Methods: This study was carried out on 30 human freshly extracted upper first premolars. After preparation of tooth surfaces for microshear bond strength test, The prepared teeth were assigned to three groups 10 of each: Group A: AH Plus sealer was used, Group B: AH Plus sealer with $0.2 \%$ Nano silver incorporated to the already mixed sealer was used, group C: AH Plus sealer in addition to $0.5 \%$ Nano silver incorporated to the already mixed sealer was used. A shear load with tensile mode of force was applied via materials testing machine, Micro-shear bond strength was measured. For solubility test 30 PVC rings with $20 \mathrm{~mm}$ in internal diameter and $5 \mathrm{~mm}$ in thickness were placed onto a thin cellophane sheet supported by a glass plate and filled with sealers as follows: Group A, 10 rings filled with AH Plus sealer mixed according to the manufacturer's instructions. Group B, 10 rings filled with AH Plus sealer mixed according to the manufacturer's instructions, in addition to $0.2 \%$ Nano silver incorporated to the already mixed sealer. Group C, 10 rings filled with AH Plus sealer mixed according to the manufacturer's instructions, in addition to $0.5 \%$ Nano silver has incorporated to the already mixed sealer. The samples were kept in an environment with temperature of $37^{\circ} \mathrm{C}$ for up to three times the setting time of each sealer group. After that, the samples were removed from the rings. Each sample was weighed on precision scale and suspended through the nylon thread inside a large opening flask containing $50 \mathrm{ml}$ of ultrapure water and all samples were maintained into the incubator at $37^{\circ} \mathrm{C}$ for 7 days. Then the samples were placed into desiccators for 24 hours for new weighing. The difference between the first and the second weight represents the mass loss for each of the specimens.
\end{abstract}

Results: Group A showed the highest mean value of microshear bond strength among all groups. Group B showed a mean value of microshear bond strength, lower than Group A and there was a statistically significant difference between them, but was higher than that of Group C and there was no statistically significant difference between these two groups B and C. Group C showed

\footnotetext{
* Lecturer in Endodontics, Endodontic Department, Faculty of Dentistry October 6 University.

** Lecturer in Biomaterials, Biomaterials Department, Faculty of Dentistry October 6 University.

*** Assistant Professor in Endodontics, Endodontic Department, Faculty of Dental Medicine, MSA University.
} 
the least mean value of microshear bond strength among all groups, it showed statistically significant difference with group A, and although it was also lower than Group B but there was no statistically significant difference between them. For solubility test group C showed the least mean value of solubility among all groups, it showed statistically significant difference with group A, and although it was also lower than Group B but there was no statistically significant difference between them.

Conclusion: The results of the present study showed that the incorporation of $0.2 \% \& 0.5 \%$ nano silver particles to the already mixed $\mathrm{AH}$ plus sealer although decreased the microshear bond strength to dentin but it increased the resistance of the sealer to solubility..

KEYWORDS: AH plus sealer, Nano silver, shear bond strength, endodontic sealer solubility

\section{INTRODUCTION}

The key to successful endodontic treatment is the thorough cleaning and shaping of the root canal system and placement of fluid tight seal obturation. Root canal sealers work as lubricants for gutta percha cones, adhesives for gutta-percha and dentin, assist in filling irregularities in canal walls and fill additional canals. ${ }^{[1],[2]}$ An important requirement of the root canal sealers is the ability to adhere to dentin. This adhesiveness should prevent fluid percolation between the gutta-percha and the canal wall in static condition, ${ }^{[3]}$ and it should prevent dislodgement of the root filling during the functional situation, thereby reducing the risk of contamination. ${ }^{[4]}$ Nowadays, it has been available in dental market many sealers with different formulations, and consequently different physical and chemical properties. ${ }^{[5]}$ Endodontic sealers can be classified into: resin, zinc oxide and eugenol, calcium hydroxide, and glass ionomer cement based sealers. A proper bond between the root filling materials and the dentin walls should provide an effective barrier against reinfection. Epoxy resin-based sealers have proven their capability in this respect in many in vitro and in vivo investigations. ${ }^{[6,7]}$

Numerous studies have examined the adhesion of different types of root canal sealers to root dentin and gutta-percha. ${ }^{(8,9,10,11,12,13)}$ Although the American Dental Association ${ }^{(14)}$ has issued a series of regulations and tests for study of the physical properties of root canal sealers, adhesion tests have not yet been standardized because no agreement on test parameters has been reached among researchers. The shear bond strength (SBS) test, in which the force is, applied parallel to the interface between the material and the tested surface. ${ }^{(15)}$ seems to be the simplest, most effective and reproducible. It was initially developed to evaluate the bonding of endodontic sealers to dentin and gutta-percha. ${ }^{[16]}$, ${ }^{[17]}$ In comparison with introducing new, adhesive materials to fill root canals (successful dentin adhesives have been available since the 1980's), adding Nano silver to resin sealers seems an innovative idea. Some studies of the antibacterial effect of dental materials incorporating silver were made. ${ }^{[18,19,20-21]}$ The aim of present study was to compare the micro shear bond strength and the solubility of resin sealer with or without the addition of Nano silver.

\section{MATERIALS AND METHODS}

Resin-based sealer AH Plus was chosen to be used in this study. AH Plus (Dentsply De Trey, Germany) is an epoxy resin-based cement which is a paste-paste type material. Paste A (epoxide paste) consists of two epoxy resins, calcium tunngstate and zirconium dioxide. Paste B (amine paste) also contains calcium tungstate, zirconium oxide plus silicone dioxide. 
Nano silver particles solution was supplied from NanoTech Center (Dreamland, 6 Oct, Cairo) in a concentration of 2200 part/million. Nano silver particles are insoluble particles smaller than $100 \mathrm{~nm}$ in size.

\section{Evaluation of the microshear bond strength}

This study was carried out on 30 human freshly extracted upper first premolars. In order to achieve a smooth, flat dentin surface for microshear bond strength test; teeth were stored in distilled water at $37^{\circ} \mathrm{C}$ for 24 hours to achieve thorough wetting then mesial surfaces were wet-ground with $\# 600$ grit silicon carbide paper in long axis direction( according ISO 11405). They were embedded then in Futura Self acrylic resin and placed in square Teflon templates $(3 \mathrm{~cm} \times 3 \mathrm{~cm} \times 2 \mathrm{~cm})$. All samples were rinsed several times with $2 \% \mathrm{NaOCl}$ and finally 0.9 $\mathrm{NaCl}$, and then gently dried with air syringe.

Three mixing pads were prepared, equal amounts of AH Plus was mixed on each pad according to the manufacturer's instructions, the first was mixed purely while in the second group $0.2 \%$ Nano silver was incorporated to the already mixed sealer while in the third $0.5 \%$ was incorporated to the already mixed sealer.

The prepared teeth were assigned to three groups (10 teeth each) :

Group A: AH Plus sealer was used.

Group B: AH Plus sealer with 0.2\% Nano silver incorporated to the already mixed sealer was used.

Group C: AH Plus sealer in addition to $0.5 \%$ Nano silver incorporated to the already mixed sealer was used.

The materials being tested were placed in a $4 \mathrm{~mm}$ diameter round hole, prepared in a silicon mould which was placed on the teeth surfaces of each group, in the center of dentin. The materials being tested formed cylinders $2 \mathrm{~mm}$ high and $4 \mathrm{~mm}$ in diameter, with a circular contact area with dentin ranging from 11 to $14 \mathrm{~mm}^{2}$.
After initial setting, the samples were transferred to an incubator at $37^{\circ} \mathrm{C}$ for 48 hours. Silicone forms were removed just before testing.

Each acrylic embedded tooth with the bonded tested material cylinders was secured with tightening screws to the lower fixed compartment of the materials testing machine (Model 3345; Instron Universal Testing Machine, England Instruments with a load cell of $500 \mathrm{~N}$ and data were recorded using computer software BlueHill 3 Instron). A loop prepared from an orthodontic wire $(0.14 \mathrm{~mm}$ in diameter) was wrapped around the bonded cylinder assembly as close as possible to the base of the cylinder and aligned with the loading axis of the upper movable compartment of the testing machine.

A shear load with tensile mode of force was applied via materials testing machine at a crosshead speed of $0.5 \mathrm{~mm} / \mathrm{min}$. the relatively slow crosshead was selected in order to produce a shear bonding force that resulted in de-bonding of the tested material cylinders along the dentin-sealer interface. The load required for de-bonding was recorded in Newton.

Micro-shear bond strength calculation was measured as follows; the load at failure divided by the bonding area to express the bond strength in MPa:

$\delta=P / \pi r 2$

$\delta$ is the bond strength in $\mathrm{MPa}$

$\mathrm{P}$ is the load at failure in Newton

$\pi=3.14$

$\mathrm{r}=$ radius of cylinder of the tested material.

\section{Solubility test:}

PVC rings with $20 \mathrm{~mm}$ in internal diameter and $5 \mathrm{~mm}$ in thickness were employed. The rings were placed onto a thin cellophane sheet supported by a glass plate and filled with sealers as follows:

Group A: 10 rings filled with $\mathrm{AH}$ Plus sealer mixed according to the manufacturer's instructions. 


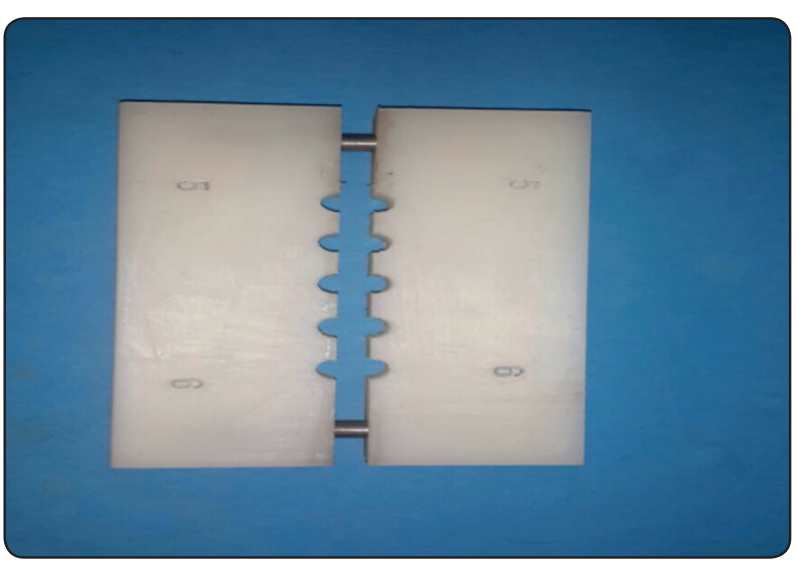

Fig. (1) Showing the mould used to form the sealers cylinders

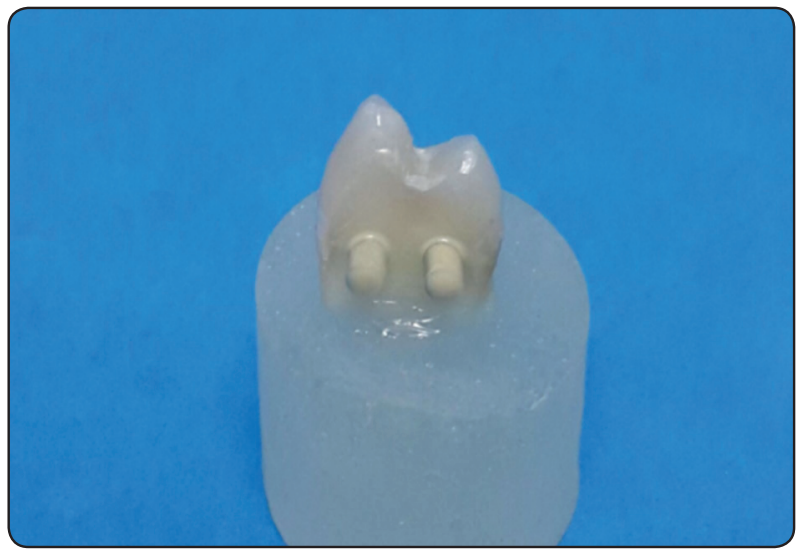

Fig. (2) Showing the tooth in acrylic block with the bonded sealers cylinders

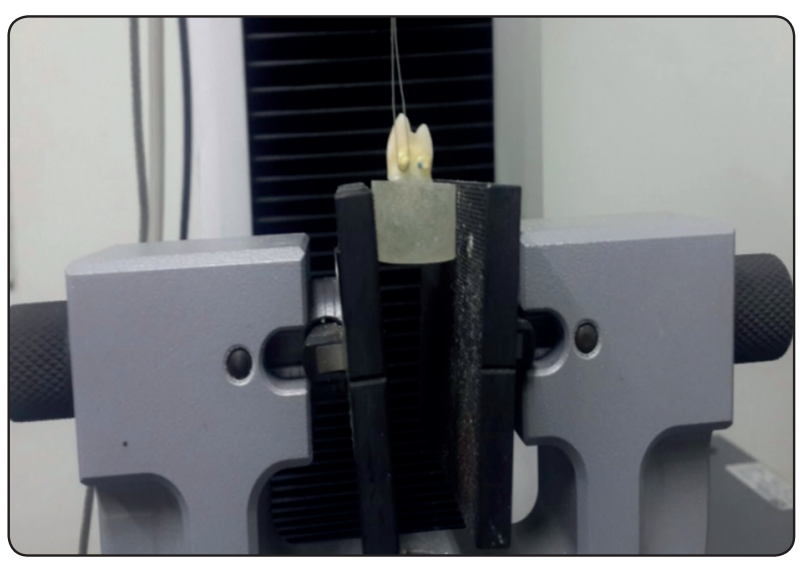

Fig. (3) Showing the Instron machine during the force loading.
Group B: : 10 rings filled with AH Plus sealer mixed according to the manufacturer's instructions in addition to $0.2 \%$ Nano silver incorporated to the already mixed sealer.

Group C: 10 rings filled with $\mathrm{AH}$ Plus sealer mixed according to the manufacturer's instructions in addition to $0.5 \%$ Nano silver incorporated to the already mixed sealer

Just after that, a nylon thread with about 0.5 $\mathrm{mm}$ in diameter with the material mass and another cellophane sheet and glass plate were placed onto the samples filled with the sealers mix. A mass of $100 \mathrm{~g}$ was placed over this set. The samples were kept in an environment with temperature of $37^{\circ} \mathrm{C}$ for up to three times the setting time of each sealer group. After that, the samples were removed from the rings.

Each sample was weighed in precision scale (Ohaus Adventure - Toledo do Brasil, Sặo Bernardo do Campo, SP. Brasil) and suspended through the nylon thread inside a large opening flask containing $50 \mathrm{ml}$ of ultrapure water. The ring was then placed into it without contacting the flasks walls. These samples were maintained into an incubator at $37^{\circ} \mathrm{C}$ for seven days. Elapsed that period, the samples were removed from the flask and washed in deionized water to remove the possible residues. Then the samples were placed into desiccators for 24 hours for new weighing. The difference between the first and the second weight represents the mass loss for each of the specimens.

\section{RESULTS}

\section{Statistical analysis}

Data were expressed as mean \pm SD. Comparison between mean values of different parameters in three studied groups were performed using KruskalWallis ANOVA test followed by Mann-Whitney test if significant results were recorded. Statistical Package for Social Sciences (SPSS) computer 
program (version 19 windows) was used for data analysis. $\mathrm{P}$ value $\leq 0.05$ was considered significant and $<0.01$ was considered highly significant.

\section{Results of the evaluation of the Microshear bond strength}

Group A showed the highest mean value of microshear bond strength $(5.13 \pm 1.33 \mathrm{MPa})$ among all groups. Group B showed a mean value of microshear bond strength equals to $(4.31 \pm 0.97$ MPa) which was lower than Group A and there was statistically significant difference between them but was higher than that of Group $\mathrm{C}$ which showed a mean value of microshear bond strength equals to $(3.70 \pm 0.80 \mathrm{MPa})$ and there was no statistically significant difference between them. Group C showed the least mean value of microshear bond strength among all groups, it showed statistically significant difference with group $\mathrm{A}$, and although it was also lower than Group B but there was no statistically significant difference between them.

TABLE (1) Showing mean values of Microshear bond strength in MPa in the three studied groups.

\begin{tabular}{|l|c|c|c|}
\hline & Group A & Group B & Group C \\
\hline Mean & 5.13 & 4.31 & 3.70 \\
\hline Std. Deviation & 1.33 & 0.97 & 0.80 \\
\hline Std. error & 0.54 & 0.40 & 0.33 \\
\hline Minimum & 3.32 & 2.79 & 2.39 \\
\hline Maximum & 6.70 & 5.65 & 4.57 \\
\hline
\end{tabular}

TABLE (2) Comparison between mean values of Microshear bond strength in the three studied groups.

\begin{tabular}{|c|c|c|c|}
\hline & Group A & Group B & Group C \\
\hline Mean \pm SD & $5.13 \pm 1.33$ & $4.31 \pm 0.9^{\mathrm{a}}$ & $3.70 \pm 0.80^{\mathrm{a}}$ \\
\hline
\end{tabular}

p>0.05= not significant. $\quad{ }^{a} p<0.05$ relative to Group $A$.

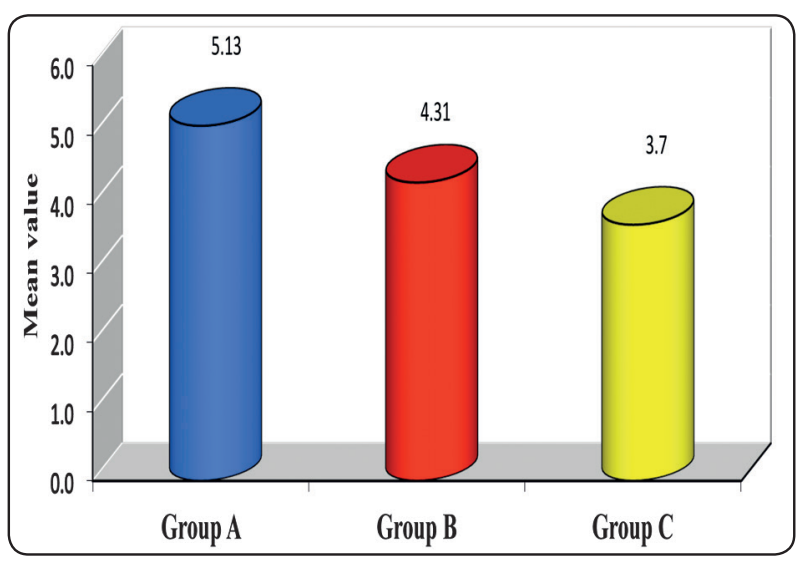

Fig. (4) Mean values of Microshear bond strength in different studied groups.

\section{Results of the Solubility test}

Group A showed the highest mean value of solubility $(0.25 \pm 0.05)$ among all groups. Group $B$ showed a mean value of solubility equals to $(0.19 \pm 0.05)$ which was lower than Group A and there was statistically significant difference between them but was higher than that of Group C which showed a mean value of solubility equals to $(0.17 \pm 0.06)$ and there was no statistically significant difference between them. Group C showed the least mean value of solubility among all groups, it showed statistically significant difference with group A, and although it was also lower than Group B but there was no statistically significant difference between them.

TABLE (3) Showing mean values of the solubility test in the three studied groups.

\begin{tabular}{|c|c|c|c|}
\hline & Group A & Group B & Group C \\
\hline Mean & 0.25 & 0.19 & 0.17 \\
\hline Std. Deviation & 0.05 & 0.05 & 0.06 \\
\hline Std. error & 0.02 & 0.02 & 0.03 \\
\hline Minimum & 0.18 & 0.13 & 0.07 \\
\hline Maximum & 0.31 & 0.24 & 0.24 \\
\hline
\end{tabular}


TABLE (4) Comparison between mean values of the solubility in the three studied groups.

\begin{tabular}{|c|c|c|c|}
\hline & Group A & Group B & Group C \\
\hline Mean \pm SD & $0.25 \pm 0.05$ & $0.19 \pm 0.05 \mathrm{a}$ & $0.17 \pm 0.06 \mathrm{a}$ \\
\hline
\end{tabular}

$p>0.05=$ not significant. $\quad$ ap $<0.05$ relative to Group $A$.

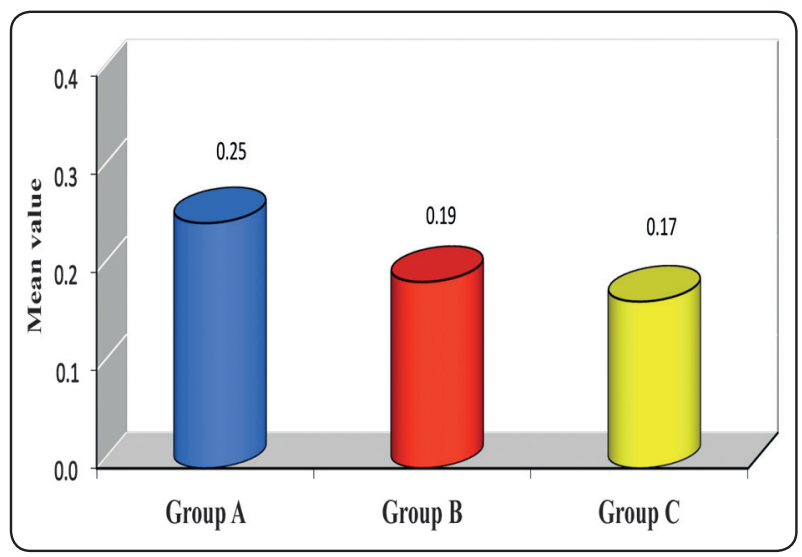

Fig. (5) Mean values of the solubility test in different studied groups.

\section{DISCUSSION}

Three-dimensional obturation of the root canal systems is one of the important objectives of endodontic treatment by preventing the reinfection of the canal and, therefore; maintaining the health status of the periapical tissues. Since the proper selection of a root canal sealer may influence the success of endodontic therapy; the biological and mechanical properties of different endodontic sealers have been extensively investigated. The root canal sealers are subject to International Standards and national regulations regarding their physical properties, but there is no agreement among researchers on adhesion testing, in other words, these tests are not standardized ${ }^{(22)}$. The methods for measuring shear strength are the simplest, most effective and reproducible. They were developed to evaluate and measure the bonding of dentin to endodontic sealers. Although numerous types of sealers have been used, the development of adhesive, resin-based filling material with better properties could increase the rate of endodontic therapy success ${ }^{(23)}$. In the present study, flat surfaces of dentin were used to measure the shear bond strength of the selected sealers to the dentin; using flat surfaces will ease specimen standardization, which allows comparing the bond strength of root canal sealers to dentin. The load was applied perpendicular to the direction of the dentin tubules, since it simulates the real forces that act inside the root canal system. Eventually the strength of root canal sealers must be adequate and studies showed that uniform distribution of highly separated nanoparticles into dental resins/composites could significantly improve the mechanical properties of the resins/ composites. ${ }^{(24)}$ Nano silver is metallic silver, which is distributed uniformly on the surface of the dental materials. It does not cause its corrosion or changes its color. Sufficient Nano silver was added into the root filling materials to prevent further spread of bacteria and was highly biocompatible. ${ }^{[25]}$ -

For these reasons we decided to incorporate silver nanoparticles $(0.2 \%, 0.5 \%)$ in to $\mathrm{AH}$ plus resin sealers and evaluating the solubility and the micro shear bond strength of this material to dentin. In the present study it was shown that the addition if $0.2 \% \& 0.5 \%$ Nano silver to the already mixed $\mathrm{AH}$ plus mixed sealer can lower the microshear bond strength to root dentin but at the same time it decresed the rate of solubility if the sealer.

AH Plus sealer makes chemical bond to dentine on the other hand nano silver as metal particles don't form this chemical bond to dentine which explains the decrease of the bond strength between the sealer and dentine in case of the incorporation of silver nano particles with the sealer mix. The results of this study, concerning the shear bond strength came in conjugation with Akhavan et al. ${ }^{(26)}$ who found the incorporation of nano silver particles containing $1 \& 5 \%$ silver can maintain or mildly reduce the micro 
shear bond strength of orthodontic adhesives. Also Chladeket et al. ${ }^{(27)}$ showed that adding nano silver particles to the composite resin can lower the bond to dentin but still didn't render worse mechanical properties than those of the composites used without the incorporation of nano silver particles. However Mahrous et al. ${ }^{(28)}$ concluded that silver nano particles incorporation within the acrylic resin denture base material can improve mechanical properties of resin including the viscoelasticity.

Cheng et al. ${ }^{[29]}$ reported the effect of AgNPs incorporation, at different concentrations, to a composite resin, in order to investigate its mechanical properties and biofilm formation. In that study, composites were synthesized with AgNPs at $0.028,0.042,0.088$, and $0.175 \%$. Mechanical properties of composites with AgNPs at $0.028 \%$ and $0.042 \%$ were similar to those with no AgNPs. Besides that, counts of colony forming units (CFU) for total streptococci and S. mutans, using AgNPs at $0.042 \%$, were $75 \%$ smaller than the control group without AgNPs. These data suggest that AgNPs incorporation to composite resins enables good mechanical properties and notable antimicrobial potential, even at low concentration. As well as, Melo et al. ${ }^{[30]}$ who evaluated the influence of AgNPs incorporation on bond strength to dental substrate added AgNPs, at $0.1 \%$ by mass, to an adhesive system. The results have shown that AgNPs did not compromise the bond strength, at the same time that it decreased metabolic activity on biofilm, compared to control group without AgNPs.

Concerning the sealer solubility, AH Plus sealer in addition to Nano silver showed resistance to solubility higher than $\mathrm{AH}$ plus sealer without Nano silver. Addition of insoluble metallic nano silver particles decreases the solubility of the resin sealer which occurs mainly in the organic matrix of the sealer. This result is in agreement with study developed by Chladeket et al. (27) who assured that the addition of low concentrations of nano silver to soft lining material decresed the solubility and increased the hardness. Also Deus et al. (31) who showed that GuttaFlow has nano silver in its composition distributed uniformly on the surface of the filling and It does not cause corrosion or color changes in the GuttaFlow.

\section{CONCLUSION}

The results if the present study showed that the incorporation of $0.2 \% \& 0.5 \%$ nano silver to the already mixed $\mathrm{AH}$ plus sealer although decreased the mucroshear bond strength to dentin but it increased the resistance of the sealer to solubility.

\section{REFERENCES}

1. Branstetter J., Fraunhofer J.A., The physical properties and sealing action of endodontic sealer cements: a review of the literature, J. Endod., 1982, 8, 312-316.

2. Craig R.G., Dental materials. A problem-oriented approach, The C.V. Mosby Company, 1978, St. Louis, USA, 243-251.

3. Orstavik D., Eriksen H.M., Beyer-Olsen E.M., Adhesive properties and leakage of root canal sealers in vitro, Int. Endod. J., 1983, 31, 275-281.

4. STEWART G.G., A comparative study of three root sealing agents (Part I), Oral Surg. Oral Med. Oral Pathol., 1958, 11, 1029-1041.

5. Leonardi DP, Battisti JC, Klimiont DT, Tomazinho PH, Baratto-Filho F, Haragushiku GA et al. Avaliação in vitro da ação antimicrobiana de alguns cimentos endodônticos. RSBO. 2009;6:367-73.

6. Cohen B.I., Volovich Y., Musikant B.L., Deutsch A., Shear bond strength for four endodontic sealers, Endod. Prac., $2002,5,9-14$.

7. Lee K., Williams M., Camps J., Pashley D., Adhesion of endodontic sealers to dentin and gutta percha, J. Endod., 2002, 28, 684-688

8. Bouillaguet S, Troesch S, Wataha JC, Krejci I, Meyer J-M, Pashley DH. Microtensile bond strength between adhesive cements and root canal dentin.Dent Mater. 2003; 19:199-205. 
9. Hiraishi N, Papacchini F, Loushine RJ, Weller RN, Ferrari M, Pashley DH, et al. Shear bond strength of Resilon to a methacrylate-based root canal sealer. Int Endod J. 2005;38:753-763.

10. Saleh IM, Ruyter E, Nat R, Haapasalo PMP, Ørstavik D. Adhesion of endodontic sealers: scanning electron microscopy and energy dispersive spectroscopy. J Endod.2003;29:595-601.

11. Saleh IM, Ruyter IE, Haapasalo M, Ørstavik D. The effects of dentine pretreatment on the adhesion of root canal sealers. Int Endod J. 2002;35:859-866.

12. Sevimay S, Dalat D. Evaluation of penetration and adaptation of three different sealers: a SEM study. J Oral Rehabil. 2003;30:951-955.

13. Sousa MD, Neto, Silva Coelho FI, Marchesan MA, Alfredo E, Silva-Sousa YT. Ex vivo study of the adhesion of an epoxy-based sealer to human dentine submitted to irradiation with Er:YAG and Nd:YAG lasers. Int Endod J. 2005; 38:866-870.

14. ANSI/ADA. Specification No. 57 Endodontic Sealing Material. Chicago, USA: ANSI/ADA; 2000.

15. Dickens SH, Milos MF. Relationship of dentin shear bond strengths to different laboratory test designs. Am J Dent.2002;3:185-192.

16. Tagger M., Tagger E., Tjan A.H.L., Bakland L.K., Measurement of adhesion of endodontic sealers to dentin, J. En-dod., 2002, 28, 351-354.

17. Tagger M., Tagger E., Tjan A.H.L., Bakland L.K., Shearing bond strength of endodontic sealers to gutta-percha, J. Endod., 2003, 29, 191-193.

18. R. Burgers, A. Eidt, R. Frankenberger et al., "The anti-adherence activity and bactericidal effect of microparticulate silver additives in composite resin materials," Archives of Oral Biology, vol. 54, no. 6, pp. 595-601, 2009.

19. S.J.Ahn, S.J.Lee, J.K.Kook, and B.S.Lim, "Experimental antimicrobial orthodontic adhesives using Nano fillers and silver nanoparticles," Dental Materials, vol. 25, no. 2, pp. 206-213, 2009.

20. K. Yoshida, M. Tanagawa, S. Matsumoto, T. Yamada, and M. Atsuta, "Antibacterial activity of resin composites with silver containing materials," European Journal of Oral Sciences, vol. 107, no. 4, pp. 290-296, 1999.
21. M. E. Odabas, , C. Cinar, G. Akc,a, I. Araz, T. Ulusu, and H. Yucel, "Short-term antimicrobial properties of mineral trioxide aggregate with incorporated silver-zeolite," Dental Traumatology, vol. 27, no. 3, pp. 189-194, 2011.

22. Bojar W, Czarnecka B, Prylinski M, Walory J. Shear bond strength of epoxy resin-based endodontic sealers to bovine dentin after ozone application. Acta Bioengineering and Biomechanics 2009; 11(3): 41-5

23. Tagger M, Tagger E, Tjan AH, Bakland LK. Shearing bond strength of endodontic sealers to gutta-percha. J Endod 2003; 29(3):191-3.

24. Tian M, Gao Y, Liu Y, Liao Y, Hedin NE, Fong H. Fabrication and evaluation of Bis-GMA/TEGDMA dental resins/composites containing nano fibrillar silicate. Dent Mater 2008;24:235-243.

25. Tyagi S, Mishra P, Tyagi P. Evolution of root canal sealers: An insight story. Eur J Gen Dent 2013;2:199-218

26. Akhavan A and Sodagar A. Investigating the effect of incorporating nanosilver/ nanohydroxyappatiete particles on the shear bond strength of orthodontic adhesives. Radiation Applications Research School, Nuclear Science AND Technology Research Institute, Tahran, Iran 2013;71(5).

27. Chladek G, Kasperski J, Barszczewska I and Zmudzki J. Sorption, Solubility, Bond Strength and Hardness of soft lining incorporated with silver nanoparticles. Int. J. Mol. Sci. 2013;14: 563-74.

28. Mahrous H and Baroudi K. Effect of silver nanoparticles incorporation on viscoelastic properties of acrylic resin denture base material. European Journal of Dentistry 2015;9:207-12.

29. L. Cheng, M. D. Weir, H. H. K. Xu et al., "Effect of amorphous calcium phosphate and silver nanocomposites on dental plaque microcosm biofilms," Journal of Biomedical Materials Research Part B: Applied Biomaterials 2012, 100. 1378-86.

30. M. A. S. Melo, L. Cheng, K. Zhang, M. D. Weir, L. K. A. Rodrigues, and H. H. K. Xu, "Novel dental adhesives containing nanoparticles of silver and amorphous calcium phosphate," Dental Materials, 2013. 29,199-210.

31. De-Deus G, Brandão MC, Fidel RA, Fidel SR. The sealing ability of GuttaFlow in oval-shaped canals: an ex vivo study using a polymicrobial leakage model. Int Endod J. 2007;40:794-9. 